\title{
Leisure and Mental Health: Sociological Study of Women Experiencing Leisure during Their Mental Illness
}

\author{
Madhu Nagla \\ Department of Sociology, Maharshi Dayanand University, India
}

Copyright $\bigcirc 2015$ by authors, all rights reserved. Authors agree that this article remains permanently open access under the terms of the Creative Commons Attribution License 4.0 International License

\begin{abstract}
This paper reports the findings from interviews with 194 mentally ill women who are seeking treatment in government hospital, Gurgoan in Haryana State, India. The respondents were questioned about their participation in leisure activities, and also about the overall experience of leisure activities. The results show that the women believed that leisure is not a part of their routine activity and hence they do not get benefits of leisure in their mental and physical health. Further, respondents reported that leisure activities gives feeling of physical and mental health and also provides experience of pleasure and freedom. It is argued that, contrary to the notion that leisure helps in maintaining good physical and mental health, doctor do not insist on participation in leisure activities. It is concluded that leisure and mental health are all embedded in the surrounding social contexts and, indeed, that leisure activities in general are inextricably entwined with their boarder cultural and structural context.
\end{abstract}

Keywords Leisure, Mental Illness, Mental Health, Women

\section{Introduction}

Globally, mental disorders are prevalent across all cultures- more than 450 million people suffer from mental disorders worldwide (Hyman et al., 2006)[1].The World Health Organization (WHO, 2001)[2] estimated that mental disorders would account for 15 per cent of the total burden of disease in the year 2020, and showed that mental disorders would be the principal cause of years lived with disability internationally. Despite advances in pharmacological and psychological treatments, the quality and adequacy of health care for persons with mental illness remain fragmented, disconnected and often inadequate, frustrating the opportunity for recovery (WHO: 2003).[3]

The World Mental Health Atlas 2011 (WHO)[4] reports that only 59 per cent people worldwide living in a country where there is dedicated Mental Health Legislation. A recent article in The Week [5] magazine reported that in India, we have over 10 crore people suffering from a mental illness. There are just 43 mental hospitals, about 4000 psychiatrists [6].Budget allocation to mental health is about as low as 1 per cent whereas experts put it close to 10 per cent [7]Much stress is laid on hospital admission and treatment. This again increases the cost of health care. No provisions are made for home treatment, recreational and leisure facilities.

Gender is a crucial determinant of health including mental health. It influences that power and control men and women have over the determinants of their mental health, including their socio-economic position, roles and social status, access to leisure activities access to resources and treatment in the society. According to MANAS Foundation(2008) [8] Indian women have more psychiatric morbidity as compared to their male counterparts because of lack of opportunities, suppression, violence/abuse, patriarchal attitude etc. As such gender is important in defining susceptibility and exposure to a number of health risks. Mental health of women is a serious sociological concern particularly in the Indian context. It is embedded in social and economic structure of the society. The Indian women face gender-based discrimination at every stage of life and in turn their psychological health becomes a cause of concern. The gender discrimination in all spheres of life also discriminate women in terms of accessibilities and opportunities of leisure available to her. Women have restricted entry into the leisure activities as it is regarded as the domain of men folk. Constant denial of leisure activities in the form of outdoor activities, watching of films, listening of music and many more other activities results into the deprivation state and in turn results into some forms of mental illnesses. It is accepted that both men and women have a fundamental right to health, thus, it becomes necessary to examine the impact of absence of leisure activities on women on her mental health.

People of all ages and abilities can experience emotions, engagement, relationships, meaning and accomplishmentall elements of positive mental health and well-being- from involvement in personally meaningful and enjoyable physical activity, recreation, leisure, sport or play. Moreover, 
it is clear that mental health and well-being is a family and community affair. Positive mental health is influenced by relationships formed with significant others, including family, friends and adult leaders (e.g., recreation leaders and coaches).At the community level such relationships contribute to social cohesion and sense of belonging, both of which are important components of mental health and well-being. Leisure and recreation pursuits can also be outlets for coping with stressful life circumstances and can provide opportunities to receive and give support, and to experience a sense of competence, and assisting people to develop skills and knowledge to overcome barriers to participation, to develop skills and self-confidence, and to experience success, positive emotions and sense of belonging are important to incorporating leisure and recreation as part of a continuum of mental health promotion, prevention, and treatment services.

Recreation and Leisure activities are essential for mental health and physical well-being across life course. They are critical components of efforts to recover from stay well when living with a chronic physical or mental health condition. Making these opportunities available to more people more often has the potential to make a significant difference to the mental health and well-being to the mental health and well-being of citizens, families and communities.

The benefits for mental health are equally important. Several studies have demonstrated links between regular physical activity and a reduction in the symptoms of mild or moderate depression, stress and anxiety. Passive leisure also has benefits for mental health by providing an outlet for the mind. It may provide physical rest, tension release and opportunities to enjoy nature and escape from the daily routine.

Participation in leisure and recreation activities can also have social benefits. It creates opportunities for socialization and contributes to social cohesion by allowing people to connect and network with others. It can also contribute to family bonding when families do things together in their leisure time.

India is the home to one of the largest number of people suffering from various mental health problems ranging from simple anxiety disorders to schizophrenia. Although about 10 per cent of disease burden is caused by poor mental health, it has not received a fraction of the attention it deserves. Poor mental health care facilities, particularly in rural areas; lack of social awareness and efforts to mitigate the impact of chronic conditions; and poor commitment and capacity have made the lives of millions of Indians with some mental health issue utterly miserable.

\section{Leisure as a Context for Active Living}

Leisure is defined as a relatively freely chosen humanistic activity and its accompanying experiences and emotions (e.g. enjoyment and happiness) that can potentially make one's life more enriched and meaningful. The meaning-seeking or meaning-making functions of leisure have a long tradition in the leisure research filed (e.g. Shaw, 1985[9]; Samdahl,
1988[10]; Hendrsons et al., 1966[11]; Kelly and Freysinger, 2000)[12].Recently, Iwasaki (2008)[13] identified key pathways to meaning-making through leisure-like pursuits in global contexts. He showed that in people's quest for a meaningful life, these leisure-generated pathways seem to simultaneously involve both 'remedying the bad' (e.g. coping with/healing from stressful or traumatic experiences, reducing suffering) and 'enhancing the good' (e.g. promoting life satisfaction and life quality) through facilitating, for example, positive emotions, identities, spirituality, connections and a harmony, human strengths and resilience, and learning and human development across the lifespan. Overall these notions of leisure emphasize: (a) meaning oriented emotional, spiritual, social and cultural properties of leisure that reflect a broader and humanistic perspective the physical activity alone, and (b) the role of meaning-making through leisure in promoting active living, health and life quality for people including individuals with mental illness. Leisure is a key context for active living and an important pathway toward recovery, health promotion and life-quality enhancement. Leisure represents broad aspects of human functioning including emotional, spiritual, social, cultural and physical elements. The forms that leisure expressions take (e.g. sport, exercise, art, crafts, visits with friends) are secondary to the meanings derived from and associated with the leisure experiences, and it is the outcomes/meanings derived that present the potential contributions to these pathways ( Iwasaki et. al., : 2010)[14]

\section{Theoretical Paradigm}

Leisure is a way of life reflecting more clearly our basic needs and higher potential as human being. More meaningful leisure activities and a wider acceptance of a right to recreation could reduce the significance to us of work and of affluence for its own sake (Hookway: 1978)[15].

Miller and Robinson (1963)[16] believe that leisure and recreation are cultural universals, being found as common elements in the behaviour of individuals in all societies; however Kaplan's (1960)[17] approach explains the functions of leisure. Nakhooda (1961)[18] puts leisure and recreation in the category which involves freedom of choice and voluntary participation in any activity, leisure can be harmful if the right kind of activity is not chosen. In her opinion, to make a judicious use of leisure recreation becomes necessary. In the opinion of Finlay (1967)[19] recreation includes many activities that are usually not thought of as play-music, drama, the crafts, every free activity and especially creative activity for the enrichment of life. Roberts (1970)[20] states that since in industrial revolution a general process of structural differentiation within society has taken place with special institutions emerging to centre to the needs such as education and social welfare which were previously catered multipurpose groups and organizations. Leisure is just one amongst man's activity which has been subjected to a process of structural differentiations.

Leisure as a social phenomenon can be understood and 
explained only in the context of a social organization. Social structure influences the nature and form of leisure and its activities. In a given society at a particular time, it allows, dictates, or is conducive to, a particular mode of leisure. It is not only determines the form and nature of leisure but also determines the extent and limit of participation whether any person would be allowed to participate or not would depend on the social status, gender in a given society (Modi: 1985)[21].On the other hand, leisure itself helps in generating new structures and social norms. History abounds in instances which support the contention that social structure influences the nature and form of social norms and generated by leisure.

Foucault argues that social reality is created in various ways through the activities of people. The resulting social reality provides a discourse, which is a way of conceptualizing an issue and provides a way of conceptualizing an issue and provides a framework for discussion and action. Mental illness is no longer considered an illness but a reversible disease, this does not mean that disorder is not severe enough to require that sufferer receive government assistance, more resources and more help in general. This assistance, however, must be geared toward improvement, not perpetual inadequacy and exclusion. In fact, the idea that mental disorders are reversible would tend to call for more financial and structural interventions, such as psychotherapy, better work opportunities, adequate leisure and all the features of a healthy society. An important thing to consider is that the narrative of mental illness has not been successful in helping sufferers and, indeed, research and evidence show that cases of mental illness are increasing annually, adding substantially to society's burden, which indicates that mental illness is largely constructed by dominant Western ideology. Concept of madness is a social construction that is regulated, reproduced, maintained and elaborated on by social structures that perpetuate the myths and ideology of mental illness. The paradigm of mental illness as disease as endured over centuries. Rationality is the opposite of madness which is based on scientific method has reduced over emotional and spiritual drives (Foucault: 1973) [22].

\section{Review of Literature}

Leisure's potential has increasingly been shown in a series of empirical research. For example, Lloyd (Lloyd et al., 2007) [23] study with 44 Australian clubhouse members with mental illness found a significant association between leisure motivation and recovery. Lloyd's findings are consistent with Hodgson and Lloyd's (2002)[24] qualitative study showing that the involvement in leisure activities play a vital role in relapse prevention for individuals with dual diagnosis of mental illness and substance misuse, and with Moloney (2002)[25] and Ryan (2002)[26] who emphasized that the engagement in leisure is instrumental in a journey for recovery from a consumer perspective. Trauer et al., (1998) [27]in their study with 55 clients who had serious mental illness reported positive effects of leisure on intellectual stimulation, relaxation and enjoyable relationships with others. Frances's (2006)[28] evidence-based review highlighted the role of outdoor recreation as a vital therapeutic means of people with mental illness, particularly its role in facilitating positive identity and life quality. Babiss' ethnographic study of women with mental illness provided evidence that expressive activities such as art, music, writing and dance promote the process toward recovery, specifically as a vehicle for learning about self and for identifying feelings one cannot express verbally. Babiss indicated that 'expression just for the sake of expression has value (2002:118)[29], while 'emphasizing 'the stunning importance of the human interaction and the human touch'[30].In fact, self-expressions and meaningful interpersonal interactions are two key benefits of leisure and recreation (Driver and Bruns, 1999)[31].

Yanos and Moos' (2007)[32] integrated model of the determinants of functioning and well-being among individuals with schizophrenia indentified leisure activities as a key dimensions of social functioning. Minato and Zemke's study (2004)[33] with 89 community residents with schizophrenia in Sapporo, Japan showed that leisure can act as a stress-reliever. Davidson et al. (2005)[34] found that going out and engaging in normal activities, having meaningful social roles and maintaining positive interpersonal relationships outside of the formal mental health systems were found as salient themes of recovery processes. Carruthers and Hood (2004)[35] stressed the role of therapeutic recreation services for individuals with mental illness in facilitating resilience, thriving and life satisfaction. Pedlar et al., (2008)[36] pointed out the importance of informal recreation opportunities (e.g. informal get-together during which women inmates with mental challenges living in a prison system spent a leisurely evening together with people from the community) rather than a conventional formalized intervention to facilitate friendship and community reintegration. The notion of leisure as an antidote to depressive symptomatology was shown in Fullagar's study (2008)[37] with 48 Australian women with depression. This study drew on post-structural feminist theories of emotion to explore the significance of leisure within women's narratives of recovery from depression.

Harvey's (2010)[38] study shows that people who engage in regular leisure-time activity of higher intensity are less likely to have symptoms of depression. The study also found that the context in which activity takes place is vital and that the social benefits associated with exercise, like increases number of friends and social support are more important in understanding how exercise may be linked to improved mental health than any biological markers of fitness. This may explain why leisure activity appears to have benefits not seen with physical activity undertaken as part of a working day. 
Gautam et al., (2007) [39] try to explore whether participation in leisure social and religious activities are related to depression and satisfaction with life in older adults of Nepal. They found that specific activity participation was a significant correlate of lower levels of depression and higher levels of satisfaction with life among older adults in Nepal. The findings explore the need for further research on activity participation in developing countries so that it can be useful for health care practitioners and those involved with the activities of aged populations in developing countries.

No studies have been identified that examine the pattern of involvement of women in various activities, and the association of activity involvement with mental health, notably depression and satisfaction with life. In India, very few opportunities are found for women to actively and openly participate in changing leisure activities because of the rigid patriarchal system.

\section{Women and Leisure}

Leisure is a basic need of human life. It provides physical and mental relaxation to person. It is equally important for both man and woman. But being the Indian society male dominated; there is a big difference between leisure of man and woman. Traditionally, women have always been treated as subordinated to men in the every aspect of life. Their place of work is confined to do household chores. They move only within the narrow sphere of kitchen cooking, child bearing and rearing and catering to the relatives, in-laws and husband. They have practically no idea of the busy world outside. On the other hand, the man is attached with the outside world. $\mathrm{He}$ is the one who is related with the economic activities of the family by doing job .It is considered that he has a right of spare time for physical and mental health while woman has no need for it. Various norms and values of society have also limited the leisure activities of women whereas not such in the case of men.

Leisure researchers have often acted as a prophet of good fortune or doom. Some have predicted a new age of leisure, a society of wealth, and a drastic reduction in working time. Kenneth Roberts (1981) [40] distinguishes an 'optimistic' scenario (increase in wealth, more gratification at work, extended leisure) from a 'pessimistic' scenario (limited growth, ecological constraints).He opts for a moderate scenario: an irrefutable growth in leisure as it occupies a larger space than before. But he reminds us of the danger of generalization. We are not moving towards a society of leisure but towards a society in which leisure is an undeniable and larger component.

Leisure activities for women have changed immeasurably in the last fifty years. While men's and children's activities largely involve play and competition, women have seemed to spend whatever leisure time they have had in the productive arts. Grandmother used to say that idle hands were the devil's workshop. Girls were encouraged to knit, sew, embroider or weave. While these activities were necessary tasks for our female ancestors, they took away leisure time as an arena of choice, if indeed any leisure time remained after families had been fed, children bathed and put to bed, and the pile of ironing and mending whittled down. Today women may choose quilting and other crafts as their favourite leisure time activities. But equally, they can go shopping, to the cinema or participate in kitty parties. And they can choose gardening as much for the love of digging into the rich earth as for the pleasure of cooking new varieties of meals.

The evolution of work activities into leisure time hobbies will keep social anthropologists filling books for years to come. So will the social revolutions that lead to profound changes in the very definition of what constitutes leisure time. If mom cooks something extra as a special dish after work, most families recognize that as dinner. If dad spends half of Sunday cooking special lunch fried rice and curry chole (chick peas), we are more likely to identify this as his gourmet-cooking hobby. But the reverse can also be true if mom has taken up chainsaw sculpture and dad is happily knitting an Afghan.

Women's lifestyles and leisure choices are no longer predictable, nor are they static. The passion and interests that are put on hold while women pursue careers, education and family responsibilities may suddenly take root when the nest is empty and time is available. Many women have chosen to include yoga and fitness routines among their lifestyle choices, recognizing the physical and mental health benefits of exercise (Nagla: 2006)[41]. The value of recreation and social participation is generally acknowledged, but for no group are these of greater health value than for women.

\section{Women and Mental Illness}

Standard histories saw the nineteenth-century medical treatment of madness (developed from the reforms of Pinel in France and Take Brothers in England) as an enlightened liberation of the mad from the ignorance and brutality of preceding ages. But, according to the Foucault (2001)[42], the new idea that the made were merely sick ("mentally" ill) and in need of medical treatment was not at all a clear improvement on earlier conceptions (e.g., the Renaissance idea that the mad were in contact with the mysterious forces of cosmic tragedy or the $17^{\text {th }}-18^{\text {th }}$ Century view of madness as renouncing of reason).Moreover, he argued that the alleged scientific neutrality of modern medical treatment of insanity is in fact covers for controlling challenges to a conventional bourgeois morality. In short, Foucault argued that what was presented as an objective, incontrovertible scientific discovery (that madness is mental illness) was in fact the product of eminently questionable social and ethical commitments.

Fullagar (2008) [43] found evidence that leisure: (a) helped one up positive experiences of self beyond the experiences with the medical/clinical treatment, (b) had transformative effects on gender identity (learning really 'who I am'), (c) generated 'hope' that there is life beyond depression and (d) enabled the women to exercise a sense of 
entitlement to play and enjoy life. Importantly, recovery-oriented leisure practices involved setting new boundaries for self (e.g. personal space) and others, and elicited emotions (e.g. joy, pleasure, courage) that facilitated transformation in ways that biomedical treatments could not. Fullgar stated, 'The recovery practices adopted by women were significant not because of the "activities" themselves but in terms of the meanings that attributed to their merging identities (e.g. alone or with others)' through creative (e.g. art/craft, gardening, writing, reading, music, community, bowls, dance, Yoga, Tai Chi, swimming, mediation) and social activities (e.g. cafes, dance courses, support groups, pets, church, helping others.

\section{Mental Health Care Act}

The Lunacy Regulation Act, 1853, Indian Lunacy Act, 1912 and the Lunatic Asylum Amendment Act 1853 were some of the archaic legislations that dealt with mental illness were referred to as lunatics or idiots thereby treating them as persons who were extremely dangerous for the mainstream society. It was in 1920, that the name mental hospital was substituted for Lunatic Asylums.

The Mental Health Act, 1987 was a positive step in ameliorating the conditions of persons with mental illness in India. The enactment of the Mental Health Act brought along with it a lot of positive changes from the erstwhile draconian legislations yet has left a lot to be done.

The National Health Policy 2002 also dealt with mental health, recognizing that mental health disorders have much more to them than what meets the age having serious bearing on the quality of life of the person affected by it. The plan had envisaged a network of decentralized mental health services.

India is a signatory to the convention on Rights of Persons with Disabilities 2006 and ratified the said instrument in October 2007.The convention inter alia provides that every person with disabilities has a right to respect for his or her physical and mental integrity on an equal basis with other (Article 17).

The experience with Mental Health Act, 1987 has been far from satisfying. In order to devise a strong mechanism to address the concern of persons suffering with mental illness and to ensure compliance with International instruments, the Draft Bill on Mental Health and Family Welfare known as Mental Health Care Bill 2012.The Bill seeks to protect, promote and fulfill the rights of persons with mental illness and to provide treatment care and rehabilitation to improve the capacity of the person to develop his or her potential and to facilitate his or her integration into community life.
The present study focuses on experience of women in leisure activities and its relation to the mental health of women in India. The following issues are raised for the exploratory study:

- Does engaging in leisure activities correlate with depression and satisfaction of women?

- Do women get less opportunity to actively participate in leisure activities?

- At what level the doctor suggest mentally ill women to engage/participate in leisure activities?

\section{Methods}

District Mental Health Programme (DMHP) started in Haryana in 1999 and district Kurukshetra was selected under the supervision of psychiatric department of Post Graduate Medical College of Rohtak. After the successful start of DMHP, Kurukshetra, two more districts covered in 2008 which are Hissar and Gurgoan. This study was carried out in the outpatient department of psychiatry, district hospital, Gurgoan. This is a secondary care health institution. Gurgoan district is situated in National Capital Region of Delhi, the capital of India. Gurgoan is about $32 \mathrm{~km}$ away from New Delhi, the National capital of India. Gurgoan has 12 Primary Health Centres and 75 Sub-Centres at rural level. Training programmes for medical officers and paramedical staff is a regular feature at psychiatric department of Gurgoan hospital. It is a part of district Mental Health Programme guidelines.

All new first 194 female patients of psychiatric disorders who reported to the department formed the study population for the present study. Patient's data are generated from psychiatric diagnostic disorders consisting of 242 female patients who had been diagnosed and treated in the psychiatric unit of DMHP, Gurgoan. Intensive interview is carried out with the patients and also with their relatives. Some narration given by the patients about their life sequences episodes are also presented in the form of case histories. Data are collected between May-June 2010. Since we do not have tools to measure the chronicity of mental illness, neither we are specialized in doing so, therefore, we thoroughly interacted with them and ascertained certain information in the form of episodes or certain other levels of information. Although doctors call them the precipitating factors in causing the mental illness. We have taken 194 women who are mentally ill. 


\section{Description of Sample}

Table 1. Socio-Economic Profile of the Mentally Ill Women Respondents

\begin{tabular}{|c|c|c|c|c|c|}
\hline Age-groups & $\begin{array}{l}\text { 20-30yrs } \\
35(18.04)\end{array}$ & $\begin{array}{c}\text { 31-40yrs } \\
92(47.42)\end{array}$ & $\begin{array}{l}\text { 41-50yrs } \\
53(27.31)\end{array}$ & $\begin{array}{l}\text { 51-60 yrs } \\
14(7.21)\end{array}$ & $\begin{array}{c}\text { Total } \\
194(100)\end{array}$ \\
\hline Marital-status & $\begin{array}{c}\text { Married } \\
128(65.97)\end{array}$ & $\begin{array}{c}\text { Unmarried } \\
61(31.44)\end{array}$ & $\begin{array}{l}\text { Widowed } \\
5(2.55)\end{array}$ & - & $194(100)$ \\
\hline Education & $\begin{array}{l}\text { Illiterate } \\
64(32.98)\end{array}$ & $\begin{array}{c}\text { Primary- 12 } \\
107(55.15)\end{array}$ & $\begin{array}{c}\text { Graduation-Post-graduation } \\
22(11.34)\end{array}$ & $\begin{array}{c}\text { Professional } \\
1(0.51)\end{array}$ & $194(100)$ \\
\hline Family & $\begin{array}{c}\text { Nuclear } \\
149(76.80)\end{array}$ & $\begin{array}{c}\text { Joint } \\
45(23.19)\end{array}$ & ( & - & $194(100)$ \\
\hline Nativity & $\begin{array}{c}\text { Rural } \\
85(43.81)\end{array}$ & $\begin{array}{c}\text { Urban } \\
109(56.18)\end{array}$ & - & - & $194(100)$ \\
\hline $\begin{array}{l}\text { Monthly } \\
\text { income }\end{array}$ & $\begin{array}{c}\text { Below Rs.5000 } \\
96(49.48)\end{array}$ & $\begin{array}{l}\text { Rs.5001-10000 } \\
65(33.50)\end{array}$ & $\begin{array}{c}\text { Rs. 10001- 20000 } \\
17(8.76)\end{array}$ & $\begin{array}{c}\text { More than Rs. 20000 } \\
16(8.24)\end{array}$ & $194(100)$ \\
\hline Occupation & $\begin{array}{l}\text { House Wife } \\
124(63.91)\end{array}$ & $\begin{array}{c}\text { Labourer/class IV work } \\
60(30.92)\end{array}$ & $\begin{array}{c}\text { Professionals (teachers etc.) } \\
4(2.06)\end{array}$ & $\begin{array}{c}\text { Shopkeeping /small } \\
\text { business } \\
6(3.09)\end{array}$ & $194(100)$ \\
\hline
\end{tabular}

The mental distress of women grouped according to age shows that prevalence is high in women in reproductive years. Most of the studies break off at the age of 50 years or so. Among the studies that do include old age, some showed a decrease in distress among women. However, it is also seen that widowhood brings in heightened mental distress. A study by Sandhya (1994])[44] studies the forced changes in life after widowhood.

Table- 1 depicts that in the age-group of 20-30 years, there are 35 (18.04 per cent) of the mentally patients, and in another age group of 31 to 40 years, there are 92 (47.42 per cent) cases. Thus, the majority of the cases are in the age group of 20 to 40 years which is the most active and productive years in life. However, in the age group of 41 years and above, there are 67 (34.52 per cent) of cases.

The table- 1 shows the prevalence of mental distress and several other socio-economic variables. It is seen that symptom rate is linked more with being married than being single. Being widowed, separated or divorced is also linked with a higher symptom rate. All the studies show greater distress in married women as compared to married men and greater stress in single women as compared to single men. Several studies have been cited showing that marriage is a stressful occupation for women. Widowhood brings heightened mental distress. A study by Sandhya (1994) [45] studies the forced change in life after widowhood. Our study also shows that there are as many as 128 (65.97 per cent) patients, who are married as compared to 61 (31.44 per cent) are unmarried. There are only 5 ( 2.55 per cent $)$ women who are widow.

Table- 1 depicts that there are 64 (32.98 per cent) patients who are illiterate; 107 (55.15 per cent)between the education level of primary to senior secondary level; only 22 (11.34 per cent)patients are either graduate or post graduate whereas only one patients is having professional qualification.

Correlating mental illness with the structure of the family, it was noted by many of the studies that mental distress was much greater in nuclear families than joint families. Chakraborty(1990)[46]found that joint families are perceived as fostering greater emotional bonding between members, as having more care givers to take care of the vulnerable and the weak, especially women and the elderly, and as being based upon mutuality and cooperation amongst its members. These studies led to an unabated hysteria among professionals after the $1970 \mathrm{~s}$, that the greater fragmentation of Indian society into nuclear families will increase conflicts, stress and strains, particularly among the women folk. Sethi and Manchanda[(1978) [47] explain the greater stress among the female members in completely joint families as the result of the conflict emanating from the desire to loosen the traditional family ties. Chakraborty (1990)[48] argues against romanticising the joint family as these families engages in a process of positive selection thus excluding economically dependent or other vulnerable people. Since nuclear family is the trend of the urban society and Gurgoan is also regarded as high-tech city, therefore, 146 (76.80 per cent) of the our respondents are living in nuclear family and only 23.19 per cent are part of joint family system.

As in the case of family structure, the urban background is also reflected in the data gathered from the hospital. Little more than fifty per cent of mentally ill patient women are from urban background, and less then forty five per cent of are from the rural background. Most of our mentally ill patients are not working or in some cases even if they are working, they are engaged are either as labourers or in lower class occupations. The income of almost fifty per cent respondents is below Rs. 5000 per month. It may also be due to the fact that because of their poor economic background, they are in the government hospital for the treatment.

The illiterate, poor refuges, unemployed and women in low paying work or sex-workers, household maids and beggars are most vulnerable to mental distress. Studies in India have shown that even though fewer women get admitted to mental hospitals for care, the once they admitted there they stay for a longer period of time. The reason for this longer stay, range from economic reason to the attitudes of hospital towards appropriate feminine behaviour. Lobbying for easy discharge may be seen as aggressive and assertive behaviour, which is an indication that the woman has not 
recovered fully. The ideal woman patient is expected to be compliant, patient, passive, dependent and submissive. The data on occupations structure presented in Table-1 shows that majority of patients, i.e. 124 (63.91 per cent) are house wives, another 60 (30.92 per cent) are working as labourers or engaged in lower income paid occupation. The data clearly depicts that only 4 women are professionals who are school teachers and clerks and another 6 are doing very small business like shop keeping etc.

Table 2. Leisure Activities among Mentally Women

\begin{tabular}{|c|c|c|c|}
\hline Leisure Activity & $\begin{array}{c}\text { Occurrence of } \\
\text { leisure } \\
\text { activity }\end{array}$ & $\mathbf{n = 1 9 4}$ & Percentage \\
\hline Talk with & Never & 8 & 4.12 \\
Neighbors & Sometimes & 146 & 75.25 \\
& Daily & 40 & 20.61 \\
\hline \multirow{2}{*}{ Visit Friends } & Never & 10 & 5.15 \\
& Sometimes & 150 & 77.31 \\
& Daily & 34 & 17.52 \\
\hline Socialize with & Never & 29 & 14.94 \\
Others & Sometimes & 158 & 81.44 \\
& Daily & 7 & 3.60 \\
\hline Watch TV, Listen & Never & 4 & 2.06 \\
radio & Sometimes & 63 & 32.47 \\
& Daily & 127 & 65.46 \\
\hline Do Physical & Never & 133 & 68.55 \\
Exercise & Sometimes & 52 & 26.80 \\
& Daily & 9 & 4.63 \\
\hline \multirow{2}{*}{ Recite Prayers } & Never & 4 & 2.06 \\
and Bhajans & Sometimes & 21 & 21.10 .82 \\
& Daily & 169 & 87.11 \\
\hline \multirow{2}{*}{ Festival activities } & Never & 5 & 2.57 \\
& Sometimes & 170 & 87.62 \\
& Daily & 19 & 9.79 \\
\hline
\end{tabular}

The majority of females ( 75.25 per cent)in the sample reported that they spoke to their neighbours occasionally, visited friends on occasional basis (77.7 per cent), and were occasionally involved in religious activities $(77.31$ per cent).The majority of women in the sample reported singing prayers and Bhajans (87.11 per cent), listened to the radio and watched television daily (65.46 per cent).Women who never participated in any physical activities were 68.55 per cent.

Overall less than one fourth of women who participated in talking with neighbours, visit friends, socialize with others, physical exercise and participate in festival activities on daily basis except watching television/radio listening and recite prayers and bhajans.

Table 3. Overall experience of Leisure among the Mentally Ill Women

\begin{tabular}{|c|c|c|}
\hline Overall experience & $\begin{array}{c}\text { Number of } \\
\text { respondents* }\end{array}$ & Percentage \\
\hline Feeling physically healthy & 103 & 53.09 \\
\hline Feeling mentally healthy & 81 & 41.75 \\
\hline $\begin{array}{c}\text { Feeling physically and } \\
\text { mentally healthy }\end{array}$ & 133 & 68.55 \\
\hline Social time for self & 52 & 26.80 \\
\hline Experience of pleasure & 79 & 40.72 \\
\hline Individual liberty & 45 & 23.19 \\
\hline
\end{tabular}

*Multiple responses permitted
The answers came in multiple response form. Although, we do not claim that on the onset of mental illness, the non-experience of leisure is a cause of mental illness. However, we separately asked to women about their overall experience of leisure during mental illness in their life. The data reveal that the experience of majority of respondents (53.09 per cent) regarding leisure gives physical and mental alertness. They found that leisure keep people physically and mentally healthy which in turn affect their roles in the family. Fifty two or 26.80 per cent said that by experiencing leisure one could find social time for themselves, and 79 (40.72 per cent) reported that it provides an experience of pleasure in true sense. Forty five (23.19 per cent) viewed leisure as a form of individual liberation.

Table 4. Advice of Doctors for Leisure Activities Reported by Mentally Ill Women

\begin{tabular}{|c|c|c|}
\hline $\begin{array}{c}\text { Doctor's Advice for Leisure } \\
\text { Activities }\end{array}$ & $\begin{array}{c}\text { No of } \\
\text { Respondents }\end{array}$ & Percentage \\
\hline $\begin{array}{c}\text { Participation in Leisure Activity } \\
\text { should be a part of life }\end{array}$ & 16 & 8.24 \\
\hline $\begin{array}{c}\text { Doctor only casually advice for } \\
\text { participation in leisure activities }\end{array}$ & 34 & 17.52 \\
\hline $\begin{array}{c}\text { Doctor Never advised for } \\
\text { participation in any sort of leisure } \\
\text { activity }\end{array}$ & 144 & 74.22 \\
\hline Total & 194 & 100.00 \\
\hline
\end{tabular}

Since the women to whom we interviewed were seeking treatment from the hospital for their illness, therefore we asked to them about the prescription of the doctor for their illness. Regarding the medication for their illness the doctor prescribed some or other form of medicines for their treatment, however, we also curiously asked about their treatment process in the form of some extra non-medication prescription. It is quite surprisingly to note that majority of our respondents i.e. 144 (74.22 per cent) reported that they did not get any advice from the doctors regarding participation in leisure activities. Only 34 (17.52 per cent) doctors casually advised or recommended to participate in leisure activities for overcoming mental illness. Very few i.e. 16 (8.24 per cent) doctors thought that leisure should be a part of the treatment process and leisure should be an activity in the daily routine.

It is found from the interviews of the mentally ill women that majority of them i.e. 95 per cent do not completely adhere to any particular system in the curse of their treatment from mental illness. People's consultation with one faith healer to another and doctors from the private to the government hospitals may not be a matter of exercising choice but a pragmatic adaptation to the poor quality of treatment in different course of treatment and patient try hard to get the best out of what is available.

On the basis of patients' narratives regarding the treatment they received from the doctors or from the faith healers in terms of leisure activities.

The middle aged woman ( 30 years, in patient) migrated from western Uttar Pradesh belongs to poor economic 
background. She said that an allopathic doctor is giving medci8ine and faith healer is giving some type of water and powder. She was given advice for not eating certain things, but at no point of time she was advised for engaging herself in recreation and leisure activities.

A 40 year old woman from Bihar had been suffering from acute depression. The doctor admitted her in the hospital. Doctor asked her history of illness and other related episodic events in her life. She accepted that after getting admitted to the hospital she felt better may be because of the strong medicine given by doctor. However, doctor was not able to treatment her illness from the root of it. It may be that doctors are not finding the root cause of the illness and simply concentrating on the medicine part. She thinks that she wants to forget her bad past by engaging herself in leisure and social activities but unable to do it.

Another patient was a 35 years old woman from Gurgoan itself and suffering from schizophrenia. During diagnosis, she explained to the doctor about her victimization of domestic violence. Doctor prescribed medicines and asked her to take them regularly. According to her, when she takes medicines her condition is better as most of the time she feel sleepy. As and when she ignores medicines, she suffers from the illness. According to her at no point of time doctor suggest her to engage herself in recreation and leisure activities.

A 37 year old woman from nearby village in Gurgoan is suffering from depression. The doctor prescribed medicines to her for 10 days and then asked her to come again after 10 days. The woman said that she spent 3400 rupees in one month and she did not get a single medicine from the hospital. She said that if she would have spent the same money for recreation or leisure activities, she would have been cured from her illness. She asserted that her family members too are ready to spend money for her treatment but not for leisure.

From above all the interviews of women, it is clear that mentally ill women feel that leisure and recreation are important for keeping oneself mentally and physically healthy. However, neither doctors feel it necessary to prescribe or suggest leisure participation as essential for treatment nor the family members of the mentally ill find its importance in the treatment process. It may be due to the financial hardship or may be the women are kept outside the purview of the leisure activities.

\section{Conclusions}

The study of mental illness among women and leisure activity can contribute to our understanding of a number of fundamental dynamics underlying male dominant societies. Our study reveals the inseparability between the values of a society and the changing perceptions of women in visualizing the importance of leisure for mental health. The study helps to document the importance of leisure activities among women particularly in Indian society which challenges conventional gender division in leisure. Leisure alerts, it indivualises, and allows freedom of expression. The stereotypical medical prescription of doctors based on medicine also smacks of not allowing space to leisure activities for sound mental health.

\section{REFERENCES}

[1] Hyman, S. et al., (2006), (eds.), Disease Control Priorities in Developing Countries, New York, NY:Oxford University Press. P. 605-626.

[2] World Health Organization (WHO) (2001), The World Health Report 2001- Mental Health: New Understanding, New Hope.

[3] World Health Organization (2003), Investing in Mental Health, http;

//www.who.int/mental-health/media/investing-mnh.pdf.

[4] Mental Health Atlas-2011 Country Profiles (2011), www.who.int/mental_health/evidence/atlas/profiles/en/

[5] http://week.manorameonline.com/cgi-

[6] http://www.firstpist.com/living/suicide-nation-can-the-menta 1-health-bill-change-anything-in-India-503557.html.

[7] Article1,http://www un.org/en/documents/udhr/index.Shtml\#a18.

[8] MANAS Foundation (2008), State of Mental Health in Delhi: Prevalence of Psychiatric Morbidity, Subjective well-being and Patterns of Help-seeking Behaviour, New Delhi: Planning Commission.

[9] Shaw, S.M. (1985), "The Meaning of Leisure in Everyday Life”, Leisure Sciences, 7: 1-24.

[10] Samdahl, D.M. (1988), “A Symbolic Interactionist Model of Leisure: Theory and Empirical Support”, Leisure Sciences, 10: 27-39.

[11] Henderson, K.A. et al., (1996), Feminist Perspectives on Women's Leisure, State College, PA:Venture Publishing Inc.

[12] Kelly, D.A.and V.J. Freysinger (2000), $21^{\text {st }}$ Century Leisure: Current Issues, Boston, M.A.: Allyn and Bacon.

[13] Iwasaki, Y. (2008), "Pathways to Meaning-Making through Leisure in Global Contexts", Journal of Leisure Research, 40: 231-249.

[14] Iwasaki, Y.et al., (2010), "Leisure as a Context for Active Living, Recovery, Health and Life Quality for Persons with Mental Illness in a Global Context", Health Promotion International, 25, 4: 483-494.

[15] Hookway, R. (1978), Issues in Recreation, England: Penguin Books Ltd.

[16] Miller, Norman and DunaeP.Robinson (1963), The Leisure Age: Its Challenge to Recreation, California: Wadsworth Publishing Company, Inc.

[17] Kaplan, Max (1960), Leisure in American: A Social Inquiry, New York: John Wiley and Sons, Inc. 
[18] Nakhooda, Zulie (1961) Leisure and Recreation in Society, Allahabad: Kitab Mahal.

[19] Finlay, John H., cit Butler, George D. (1967) Introduction to Community Recreation, New York: McGraw-Hill Book Co. p.3.

[20] Roberts, Kenneth (1983), Youth and Leisure, London: Allen and Unwin.

[21] Modi, Ishwar (1985), Leisure, Mass Media and Social Structure, Jaipur: Rawat Publications.

[22] Foucault, Michael (1973), Madness and Civilization: A History of Insanity in the Age of Reason, New York: Vintage.

[23] Lloyd, C. et al., (2007), "The Association Between Leisure Motivation and Recovery: A Pilot Study", Australian Occupational Therapy Journal, 54:33-41.

[24] Hodgson, S. and C. Lloyd (2002), "Leisure as a Relapse Prevention Strategy", British Journal of Therapy and Rehabilitation, 9: 86-91.

[25] Moloney, T.(2002), "My Journey of Recovery", Newparadigm, 5th December.

[26] Ryan, K. (2002), "Road to Recovery". Newparadigm, $4^{\text {th }}$ December.

[27] Trauer, T. et al., (1998), "A Study of the Quality of Life of the Severely Mentally Ill”, International Journal of Social Psychiatry, 44: 79-91.

[28] Frances, K (2006), “Outdoor Recreation as an Occupation to Improve Quality of Life for People with Enduring Mental Health problems", British Journal of Occupational Therapy, 69: 182-186.

[29] Babiss, F.(2002), "An Ethnographic Study of Mental Health Treatment and Outcomes: Doing What Works", Occupational Therapy in Mental Health, 18:1-146.

[30] Babiss, F.(2002), "An Ethnographic Study of Mental Health Treatment and Outcomes: Doing What Works", Occupational Therapy in Mental Health, 18:106.

[31] Driver, B.L. and D.H. Burns (1999), "Concepts and Uses of the Benefits Approach to Leisure", in E.I. Jackson and T.L. Burton (eds.), Leisure Studies: Prospects for the Twenty-First Century, State College, PA: Venture Publishing, p. 349-369.

[32] Yanos, P.T. and R.H. Moos (2007), "Determinants of Functioning and Well-Being among Individuals with Schizophrenia: An Integrated Model", Clinical Psychology Review, 27: 58-77.

[33] Minato, Mand R. Zemke (2004), "Time Use of People with Schizophrenia Living with the Community", Occupational
Therapy International, 11: 177-191.

[34] Davidson, L. et al., (2005), "Processes of Recovery in Serious Mental Illness: Findings from a Multinational Study", American Journal of Psychiatric Rehabilitation, 8: 177-201.

[35] Carruthers, C. and C.D. Hood (2004), "The Power of the Positive: Leisure and Well-being", Therapeutic Recreation Journal, 38:225-245.

[36] Pedlar, A. et al., (2008), "Incarcerated Women and Leisure: Making Good Girls out of bad?" Therapeutic Recreation Journal, 42: 24-37.

[37] Fullagar, S. (2008), "Leisure Practices as Counter-Depressants: Emotion-Work and Emotion-play within Women's recovery from Depression", Leisure Sciences, 30: 35-52.

[38] Harvey, Samuel B. et al., (2010), "Physical activity and Common Mental Disorders", British Journal of Psychiatry, 197, 357-364.

[39] Gautam, Ramraj, Tami Saito and Ichiro and Kai (2007), "Leisure and religious activity participation and Mental Health: Gender Analysis of Older Adults in Nepal", Bio Medical Central Public Health, 7:299.

[40] Roberts, Kenneth (1981), Leisure, London: Longman.

[41] Nagla, Madhu (2006), "Yoga, Health and Leisure: Attitudes of Women in Haryana", World Leisure Journal, No.2, Volume 48, pp.23-34.

[42] Foucault, Michel (2001), Madness and Civilization: A History of Insanity in the Age of Reason, Routledge.

[43] Fullagar, S. (2008), "Leisure Practices as Counter-Depressants: Emotion-Work and Emotion-play within Women's recovery from Depression", Leisure Sciences, 30: 35-52.

[44] Sandhya( 1994 ), Widowhood: A Socio-psychiatric Study, Delhi: Mohit Publications

[45] Sandhya (1994), Widowhood: A Socio-psychiatric Study, Delhi: Mohit Publications.

[46] Chakraborty, Ajitia (1990), Social Stress and Mental Health: A Social-Psychiatric Field study of Calcutta, New Delhi: Sage Publications.

[47] Sethi, B.B. and R.Manchanda(1978), "Family Structure and Psychiatric Disorders", Indian Journal of Psychiatry, 20(3), 283-288.

[48] Chakraborty, Ajitia (1990), Social Stress and Mental Health: A Social-Psychiatric Field study of Calcutta, New Delhi: Sage Publications. 